\title{
IMPLEMENTASI PARIWISATA BERBASIS MASYARAKAT DI DESA WISATA MANGROVE SARI, KABUPATEN BREBES
}

\author{
Oleh \\ Syahrul Akbar'), Evi Novianti ${ }^{2)}$ \& Ute Lies Siti Khadijah ${ }^{3)}$ \\ 1,2,3Program Studi Magister Pariwisata Berkelanjutan, Sekolah Pascasarjana, \\ Universitas Padjadjaran, Bandung \\ Email: ${ }^{\text {Syahrul19001@mail.unpad.ac.id }}$
}

\begin{abstract}
Abstrak
Desa Wisata Mangrove Sari merupakan daya tarik wisata yang berkembang dari hasil rehabilitasi hutan mangrove di pesisir Dusun Pandansari, Desa Kaliwlingi, Kecamatan Brebes, Kabupaten Brebes. Sejak ditetapkan sebagai desa wisata pada tahun 2016 dan secara resmi dibuka pada tahun 2017, Desa Wisata Mangrove Sari menjadi salah satu daya tarik wisata favorit di Kabupaten Brebes. Sebagai salah satu daya tarik wisata, desa wisata ini menerapkan konsep pariwisata berbasis masyarakat (CBT). Penelitian ini bertujuan untuk menganalisis bagaimana penerapan konsep pariwisata berbasis masyarakat di Desa Wisata Mangrove Sari. Penelitian ini menggunakan metode kualitatif dengan pendekatan studi kasus. Data penelitian ini terdiri dari dua jenis, yaitu data primer dan data sekunder. Data primer diperoleh melalui wawancara mendalam terhadap informan kunci penelitian ini, yaitu Ketua Pokdarwis Dewi Mangrove Sari yang juga merupakan inisiator pengembangan desa wisata di Dusun Pandansari. Sedangkan data sekunder diperoleh melalui studi dokumentasi, serta penelitian-penelitian terkait Desa Wisata Mangrove Sari maupun studi tentang CBT. Hasil penelitian ini menunjukkan bahwa pengelolaan Desa Wisata Mangrove Sari dilakukan secara penuh oleh masyarakat desa setempat melalui kelembagaan pariwisata, yaitu Pokdarwis Dewi Mangrove Sari. Masyarakat berpartisipasi dalam kelompok kerja yang terdapat dalam pokdarwis tersebut. Hasil analisis juga menunjukkan tingkat partisipasi masyarakat desa berada pada pembuatan keputusan lokal.

Kata Kunci: Pariwisata Berbasis Masyarakat, CBT, Partisipasi Masyarakat, Desa Wisata, Desa Wisata Mangrove Sari
\end{abstract}

\section{PENDAHULUAN}

Desa wisata Mangrove Sari merupakan salah satu daya tarik wisata yang terletak di Dusun Pandansari, Desa Kaliwlingi, Kecamatan Brebes, Kabupaten Brebes. Desa Wisata ini memiliki potensi wisata alam berupa hutan Mangrove seluas 210 Ha. Berdasarkan studi dokumentasi dan hasil wawancara terhadap Pengelola Desa Wisata Mangrove Sari, diketahui bahwa Hutan mangrove tersebut merupakan hasil upaya bersama masyarakat Dusun Pandansari selama 10 tahun untuk keluar dari bencana abrasi yang menimpa wilayahnya.

Setelah upaya konservasi hutan mangrove dilakukan, bencana abrasi kemudian dapat ditanggulangi dan atas inisiatif masyarakat Dusun Pandansari hutan mangrove tersebut akhirnya dikembangkan menjadi daya tarik wisata yang berbasis masyarakat. Modal sosial berupa konservasi hutan mangrove ini kemudian diangkat menjadi tema Desa Wisata Mangrove Sari, yaitu "Bencana Sebagai Berkah Dengan Menanam Untuk Peningkatan Ekonomi Selaras Alam."

Desa Wisata Mangrove Sari secara kelembagaan telah mampu meraih Juara I Lomba Kelembagaan Pariwisata Tingkat Provinsi Jawa Tengah tahun 2019. Selain itu di bidang konservasi lingkungan Desa Wisata Mangrove Sari pernah menjadi Finalis Equator Prize pada tahun 2017 yang diselenggarakan oleh Equator Initiative sebagai bagian dari 
Program United Nation Development Program (UNDP).

Sebagai salah satu daya tarik wisata yang terletak di Kabupaten Brebes, Desa Wisata Mangrove Sari memiliki letak yang sangat strategis untuk menarik wisatawan dari Provinsi Jawa Barat. Menurut pengakuan Pengelola Desa Wisata Mangrove Sari, wisatawan yang berasal dari Kabupaten Kuningan merupakan wisaawan terbanyak yang mengunjungi daya tarik wisata ini. Kemudian diikuti oleh wisatawan asal Cirebon.

Dengan potensi wisatanya tersebut, Kabupaten Brebes ditetapkan sebagai salah satu Kawasan Pengembangan Pariwisata Provinsi (KPPP) Jawa Tengah, yaitu KPPP KaliguaMalahayu dan sekitarnya [1]. Selain karena Kabupaten Brebes berada di perbatasan antara Provinsi Jawa Tengah dan Provinsi Jawa Barat, kawasan ini juga memiliki potensi pengembangan pariwisata yang potensial di masa depan, salah satunya adalah Desa Wisata Mangrove Sari.

Meskipun Desa Wisata Mangrove Sari memiliki potensi wisata yang unik, serta secara kelembagaan mampu mencapai prestasi gemilang, pengelolaan Desa Wisata ini juga tak luput dari permasalahan. Berdasarkan data kunjungan ke Desa Wisata Mangrove Sari, sejak resmi beroperasi pada tahun 2016 jumlah kunjungan wisatawan menunjukkan grafik yang semakin menurun. Tercatat pada tahun 2017 jumlah kunjungan wisatawan sebanyak 209.073 kunjungan, kemudian menurun ke angka 198.735 kunjungan di tahun 2018, turun lagi menjadi 132.936 kunjungan wisatawan pada tahun 2019, dan titik terendah kunjungan wisatawan ke Desa Wisata Mangrove Sari tercatat pada tahun 2020 dengan hanya mampu menarik kunjungan wisatawan sebanyak 52.784 wisatawan.

Tren kunjungan ke Desa Wisata Mangrove Sari yang menurun diakibatkan oleh adanya kejenuhan wisatawan untuk mengunjungi kembali daya tarik wisata ini, walaupun pihak pengelola sudah berusaha untuk memperbaharui beberapa spot untuk berswafoto secara berkala [2]. Selain itu kebijakan yang dikeluarkan Pemerintah Provinsi Jawa Tengah untuk menutup daya tarik wisata yang berada di wilayah Provinsi Jawa Tengah serta Pembatasan Kegiatan Masyarakat di sektor pariwisata yang membatasi jumlah pengunjung sebanyak 30\% dari daya tampung maksimal daya tarik wisata, dalam rangka menekan penyebaran Virus COVID-19, turut memberikan andil menurunnya kunjungan wisatawan ke Desa Wisata Mangrove Sari hingga 50\% pada tahun 2020 jika dibandingkan dengan jumlah kunjungan wisatawan pada tahun 2019 sebelumnya.

Permasalahan lain yang ditemukan dalam observasi awal penelitian ini yaitu kurangnya tingkat partisipasi masyarakat dalam pengelolaan Desa Wisata Mangrove Sari. Hal ini merupakan akibat dari sebagian masyarakat yang menganggap sektor pariwisata bukan sebagai sumber utama pendapatan. Padahal partisipasi masyarakat dalam konsep pengembangan pariwisata berbasis masyarakat merupakan faktor kunci untuk mencapai suksesnya keberlanjutan dalam pembangunan pariwisata di daerah pedesaan [3], [4].

Terlepas dari masalah yang dihadapi Desa Wisata Mangrove Sari, merebaknya Pandemi COVID-19 dapat menjadi momentum bagi sektor pariwisata, khususnya Desa Wisata Mangrove Sari, untuk bangkit kembali [5] setelah mengalami keterpurukan [6]. Sebagai catatan, lebih kurang US\$ 113M kerugian yang diderita oleh maskapai penerbangan di seluruh dunia, atau 15 kali lebih banyak dibandingkan kerugian yang disebabkan oleh kasus SARS pada tahun 2002-2003 [7]. Sedangkan berdasarkan data dari Dinas Kepemudaan, Olahraga, dan Pariwisata Provinsi Jawa Tengah, pendapatan yang diperoleh dari retribusi masuk ke daya tarik wisata pada bulan Maret 2020 mengalami penurunan sebesar 90\% dari pendapatan di bulan yang sama Tahun 2019 sebagai imbas ditutupnya 597 daya tarik 
wisata dari total 639 daya tarik wisata yang tersebar di Jawa Tengah.

Momentum kebangkitan kembali sektor pariwisata dimungkinkan terjadi akibat adanya perubahan tren pariwisata dunia tidak hanya sebagai imbas dari Pandemi COVID-19 [8] melainkan juga akibat perkembangan teknologi informasi [9]. Kebijakan karantina wilayah di beberapa negara, pembatasan perjalanan udara, Pembatasan Sosial Berskala Besar di Indonesia, serta Pembatasan Kegiatan Masyarakat di Sektor Pariwisata di Jawa Tengah akan mendorong tumbuhnya wisatawan domestik di era pandemi COVID-19 dan masa setelahnya.

Fenomena global tersebut turut berperan dalam mempengaruhi preferensi wisatawan, yang semula cenderung mengunjungi destinasi wisata populer dengan tingkat kunjungan yang tinggi, kemudian berubah menjadi lebih cenderung memilih untuk berwisata di destinasi yang lebih aman (sudah menerapkan protokol kesehatan ketat), kurang populer, dekat dari tempat tinggal, serta menawarkan aktivitas utama di luar ruangan. Kesadaran wisatawan akan kegiatan berwisata yang dapat meningkatkan kesehatan seperti berjalan di tracking mangrove, bersepeda, dan olahraga air juga akan semakin meningkat [8].

Berdasarkan tinjauan terhadap penelitian terdahulu dengan tema pengembangan pariwisata berbasis masyarakat yang dilakukan pada tahun 2015-2021 diketahui belum ada penelitian yang menganalisis penerapan konsep pariwisata berbasis masyarakat di desa wisata. Penelitian terdahulu tersebut hanya menunjukkan dampak pengembangan pariwisata berbasis masyarakat terhadap modal sosial masyarakat [10]-[12], ekonomi [13][16], budaya [13], [15]-[19], dan sosioekologis [20].

Mengacu pada permasalahan yang ditemukan dalam observasi, tantangan pariwisata dunia, dan tinjauan terhadap penelitian terdahulu, maka penelitian ini bertujuan untuk menganalisis bagaimana implementasi pariwisata berbasis masyarakat di
Desa Wisata Mangrove Sari, Kabupaten Brebes.

\section{LANDASAN TEORI}

Untuk memahami bagaimana konsep pariwisata berbasis masyarakat diterapkan di Desa Wisata Mangrove Sari, dalam landasan teori ini akan dikemukakan definisi, faktor penentu keberhasilan, dan partisipasi masyarakat. Pariwisata berbasis masyarakat atau Community-Based Tourism (CBT) merupakan alat pembangunan kapasitas masyarakat yang memperkuat kemampuan masyarakat desa dalam mengelola sumberdaya pariwisata sambil memastikan keterlibatan masyarakat [21]-[23]. Batasan pengertian CBT ini menunjukkan bahwa: 1) pariwisata merupakan alat untuk mencapai masyarakat yang berdaulat dan mampu dalam mengelola sumber daya pariwisata, dan 2) masyarakat merupakan aktor utama dalam tahapan pembangunan pariwisata. Keterlibatan masyarakat dalam pembangunan pariwisata diharapkan dapat meningkatkan manfaat pembangunan pariwisata bagi masyarakat setempat, sebaliknya mengurangi dampak negatif pembangunan pariwisata terhadap masyarakat dan sumberdaya lingkungannya.

Pariwisata berbasis masyarakat juga dapat diartikan sebagai pendekatan dalam pembangunan pariwisata yang menekankan keberlanjutan sumber daya yang dikelola dan dimiliki masyarakat, meliputu sumber daya lingkungan, sosial, dan budaya, sehingga memungkinkan wisatawan untuk dapat menambah wawasannya melalui interaksi dengan masyarakat setempat, dan pembelajaran kehidupan sehari-hari masyarakat [24]. Selain menekankan pada keberlanjutan aspek lingkungan, sosial, dan budaya, Suansri juga menekankan proses pertukaran dan pemahaman budaya yang berbeda antara wisatawan dan masyarakat lokal melalui proses interaksi.

CBT juga diartikan sebagai konsep pengembangan pariwisata dalam skala yang lebih kecil, menciptakan hubungan antara 
wisatwan dengan masyarakat selaku tuan rumah, sehingga lebih sesuai untuk dikembangkan di wilayah pedesaan dan regional [25]. Konsep ini memiliki karakteristik: 1) masyarakat lokal sebagai pemilik dan pengelola sumber daya pariwisata, 2) masyarakat lokal berperan sebagai penyedia jasa dan supplier, dan 3) melakukan penafsiran terhadap komunikasi budaya dan lingkungan lokal. Hal ini mendorong masyarakat menjadi lebih kreatif untuk mengangkat kearifan lokalnya sebagai modal sosial, sehingga muncul kebanggaan terhadap kebudayaan lokal yang semakin terkikis dalam era postmodernisme ini [26].

Dalam pelaksanaannya selain peran aktif masyarakat itu sendiri, terdapat beberapa faktor yang berperan penting dalam tahapan pengembangan pariwisata berbasis masyarakat, meliputi kebijakan [3], [27], [28], organisasi eksternal [26], dan persepsi wisatawan [29]. Keberhasilan pengembangan CBT juga ditentukan oleh perencanaan, kemitraan, kapasitas masyarakat dalam menyampaikan produk wisata, dan pendanaan [14]. Selain itu kehadiran local champion [21] atau cosmopolitan leader [14] dalam mengarahkan masyarakat juga mutlak diperlukan dalam pelaksanaan pengembangan pariwisata berbasis masyarakat.

Terdapat beberapa penelitian yang menganalisis persepsi masyarakat [13], [18], [30]-[34] dan partisipasinya [4], [35]-[38] di dalam proses pengembangan pariwisata berbasis masyarakat. Partisipasi masyarakat sangat ditentukan oleh persepsinya terhadap dampak positif atau negatif pembangunan pariwisata di daerahnya. Oleh sebab itu perlu ada intervensi baik dari Pemerintah, Industri Pariwisata, maupun organisasi yang bergerak di bidang konservasi lingkungan, untuk memberikan rangsangan dan kekuatan kepada kelompok masyarakat yang mendukung pengembangan pariwisata. Sehingga dapat memimpin inisiatif, merayu masyarakat yang enggan berpartisipasi, serta memberikan energi positif kepada masyarakat yang bahkan menolak untuk terlibat dalam pengembangan pariwisata di daerahnya [33].

Partisipasi masyarakat dalam pembangunan pariwisata diartikan sebagai distribusi ulang kekuasaan terhadap masyarakat yang tadinya sama sekali tidak terlibat dalam proses-proses pembangunan, menjadi terlibat baik dalam proses mengambil keputusan, merencanakan, mengelola, serta memperoleh manfaat ekonomi [39]. Terdapat 5 (lima) jenis partisipasi masyarakat berdasarkan distribusi kekuasaan dalam mengambil keputusan, antara lain: 1) konvensional, 2) konsultatif, 3) kolaboratif, 4) kolegial, dan 5) pembuatan keputusan lokal [40].

\section{METODE PENELITIAN}

Berdasarkan fokus penelitian ini, maka metode yang digunakan dalam penelitian ini adalah studi kasus dengan pendekatan kualitatif. menggunakan pendekatan kualitatif dengan metode studi kasus. Penelitian studi kasus bertujuan untuk melakukan penyelidikan mendalam mengenai subyek tertentu untuk memberi gambaran lengkap mengenai subyek tersebut [41], [42]. Studi kasus merupakan penelitian yang dilakukan secara intensif, rinci dan mendalam mengenai suatu kasus, gejala sosial, atau unit sosial tertentu yang spesifik [43].

Data penelitian ini adalah data kualitatif yang berbentuk kata, kalimat dan gambar. Sumber data penelitian ini terdiri atas data primer dan data sekunder. Data primer merupakan data yang diperoleh dari observasi lapangan di Desa Wisata Mangrove Sari, serta hasil wawancara terhadap Ketua dan Anggota Pokdarwis Dewi Mangrove Sari. Sedangkan data sekunder merupakan data yang diperoleh dari kajian pusataka terhadap penelitian terdahulu terkait Desa Wisata Mangrove Sari, dan pariwisata berbasis masyarakat. Data yang diperoleh tersebut dianalisis dengan menggunakan model analisis data kualitatif yang meliputi 1) kondensasi data, 2) display 
data, dan 3) penarikan kesimpulan/verifikasi [44].

\section{HASIL DAN PEMBAHASAN}

Profil Desa Wisata Mangrove Sari

Desa Wisata Mangrove Sari merupakan daya tarik wisata alam berupa kawasan hutan mangrove yang terletak di Dusun Pandansari, Desa Kaliwlingi, Kecamatan Brebes, Kabupaten Brebes. Sumber daya alam desa wisata ini merupakan hasil upaya kolektif masyarakat dusun dalam rangka merehabilitasi hutan mangrove yang rusak akibat alih fungsi lahan. Pesisir dusun yang semula ditutupi oleh kawasan hutan mangrove kemudian dirubah pemanfaatannya menjadi lahan tambak udang dan permukiman warga [45]. Sebagai akibatnya, Dusun Pandansari mengalami bencana abrasi yang menyebabkan lahan tambak hilang, dan permukiman warga menjadi terendam banjir rob.

Hilangnya kawasan hutan mangrove di pesisir Dusun Pandansari membawa dampak pada lingkungan, ekonomi, dan sosial masyarakat Desa Kaliwlingi. Bencana abrasi membawa imbas terhadap lingkungan, seperti masuknya air rob ke pemukiman, rumah hancur, interusi air laut pada lahan pertanian, sehingga masyarakat Desa Kaliwlingi tidak dapat berkembang seperti masyarakat di daerah lainnya.

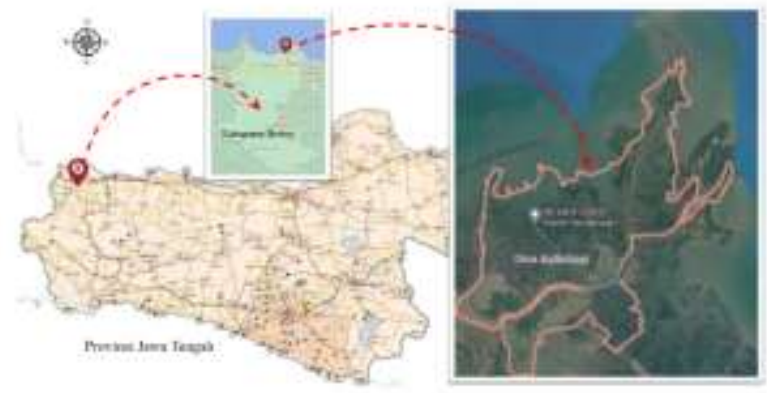

Gambar 1 Peta Desa Kaliwlingi, Kabupaten Brebes

Sumber: Hasil Olah Data Penelitian, 2021

Dampak lingkungan akibat bencana abrasi tersebut, menimbulkan tekanan ekonomi masyarakat Desa Kaliwlingi. Masuknya air rob melumpuhkan perekonomian masyarakat karena kondisi air laut yang lebih tinggi dari tambak, sehingga udang dan ikan yang dibudidayakan oleh masyarakat menjadi hilang terbawa banjir rob. Selain sektor budidaya perikanan yang terdampak, sektor pertanian pun ikut mengalami imbasnya. Petani mengalami gagal panen, dan lahan pertanian menjadi tidak produktif karena interusi air laut membuat tanah persawahan menjadi asin. Sedangkan air hujan tidak mampu menetralisir tingkat keasinan air laut yang terserap oleh tanah sawah.

Lumpuhnya perekonomian warga, mengakibatkan anak-anaknya tidak mampu mengenyam pendidikan yang baik dan layak. Anak-anak putus sekolah terpaksa ikut mencari uang dengan mengikuti orang tuanya melaut atau dikenal dengan istilah "miyang." Sehingga kualitas sumber daya manusia pun menurun, yang kemudian berkontribusi pada peningkatan pengangguran. Tingkat pendidikan dan mata pencaharian masyarakat Desa Kaliwlingi dapat dilihat pada tabel 1 dan 2 di bawah ini.

Tabel 1 Jumlah Penduduk Desa Kaliwlingi Berdasarkan Tingkat Pendidikan Tahun 2019

\begin{tabular}{|l|l|l|}
\hline No. & Tingkat Pendidikan & Jumlah \\
\hline 1. & Tidak/Belum Sekolah & 1.946 \\
\hline 2. & Belum Tamat SD/Sederajat & 2.135 \\
\hline 3. & Tamat SD/Sederajat & 2.730 \\
\hline 4. & SMP/Sederajat & 775 \\
\hline 5. & SMA/Sederajat & 331 \\
\hline 6. & Diploma I/II & 13 \\
\hline 7. & Akademi/Diploma III/Sarjana Muda & 32 \\
\hline 8. & Diploma IV/Strata I + & 28 \\
\hline
\end{tabular}

Sumber: Kecamatan Brebes Dalam Angka 2020

Tabel 2 Jumlah Penduduk Desa Kaliwlingi Berdasarkan Mata Pencaharian Tahun 2019

\begin{tabular}{|l|l|l|}
\hline No. & Mata Pencaharian & Jumlah \\
\hline 1. & PNS & 9 \\
\hline 2. & TNI/Polri & 3 \\
\hline 3. & Guru & 28 \\
\hline 4. & Pensiunan & 2 \\
\hline 5. & Petani/Perkebunan & 700 \\
\hline 6. & Buruh Tani/Perkebunan & 5.528 \\
\hline 7. & Nelayan/Perikanan & 3.156 \\
\hline 8. & Buruh Nelayan/Perikanan & 32 \\
\hline 9. & Karyawan Swasta & 108 \\
\hline 10 & Perdagangan & 19 \\
\hline 11. & Lainnya & 5.156 \\
\hline
\end{tabular}


Sumber:BPS Kab. Brebes Kecamatan Brebes Dalam Angka 2020

Dengan kondisi alam yang demikian memprihatinkan, pada tahun 2007, masyarakat Dusun Pandansari yang tergabung dalam Kelompok Masyarakat Pelestari Hutan Pesisir berembuk dengan beberapa elemen masyarat yang terdiri dari Karang Taruna, Ketua RT dan RW di Desa Kaliwlingi, Tokoh Masyarakat, dan perwakilan masyarakat Desa Kaliwlingi untuk mencarikan solusi atas kondisi alam yang telah merusak lingkungan dan permukiman penduduk. Hasil pertemuan tersebut berupa keputusan untuk melakukan upaya rehabilitasi hutan mangrove dengan menanam \pm 150.000 bibit mangrove di lahan seluas 1,5 ha. Upaya rehabilitasi hutan mangrove dilakukan melalui beberapa tahapan, meliputi: 1) identifikasi lokasi dan bibit, 2) menentukan musim tanam, 3) menentukan pola tanam, 4) melakukan penanaman, dan 5) melakukan pengawasan.

Meskipun keputusan untuk melakukan usaha rehabilitasi hutan mangrove tersebut telah melibatkan beberapa elemen masyarakat di Desa Kaliwlingi, masih ada sebagian masyarakat yang menolak untuk terlibat dalam usaha rehabilitasi hutan mangrove tersebut. Sebagian masyarakat yang menolak, memiliki pandangan bahwa banjir rob merupakan bencana yang tidak dapat dibendung, maka upaya membendung banjir rob dengan hutan mangrove merupakan kegiatan yang sia-sia. Namun penolakan yang timbul dari sebagian masyarakat tersebut, tidak menyurutkan semangat Rusjan dan Mashadi bersama-sama dengan Kelompok Masyarakat Pelestari Hutan Pesisir untuk tetap melakukan penanaman pohon mangrove. Mereka berprinsip hidup harus bermanfaat untuk orang lain, dan "Gusti Allah Mboten Sare," (Allah tidak tidur) secuil apapun yang dilakukan oleh manusia pasti ada imbalannya.

Berbekal prinsip hidup tersebut, baik Rusjan maupun Mashadi secara konsisten terus mengajak dan mengedukasi masyarakat setempat dengan memberikan pemahaman bahwa mangrove yang tumbuh dengan baik, akarnya dapat saling mengikat dan menguatkan sehingga dapat menjadi penghalang ombak. Kawasan hutan mangrove dapat berperan dan berfungsi sebagai: 1) pelindung garis pantai dari abrasi dan tsunami, 2) pencegah intrusi air laut, 3) penyimpan karbon yang tinggi, 4) penyerap polutan, 5) tempat berpijah aneka biota laut, 6) tempat berlindung dan berkembang biak berbagai jenis fauna ekosistem air payau, 7) penyedia hasil hutan berupa kayu dan non kayu, 8) pengembangan ekowisata, dan 9) lokasi penelitian dan pendidikan lingkungan (sumber dokumen Pokdarwis Dewi Mangrove Sari).

Upaya Rusjan, Mashadi dan Kelompok Masyarakat Pelestari Hutan Pesisir dalam melakukan rehabilitasi kawasan hutan mangrove di Dusun Kaliwlingi akhirnya membuahkan hasil. Terdapat lebih kurang 250 ha ekosistem mangrove hasil rehabilitasi yang dilestarikan. Keberhasilan pelaksanaan rehabilitasi kawasan hutan mangrove ini kemudian didorong untuk dapat menghasilkan nilai positif dalam meningkatkan kesejahteraan masyarakat. Menurut yang disampaikan oleh Rusjan dalam wawancara yang dilakukan pada tanggal 27 Februari 2021, pemanfaatan nilai tambah kawasan hutan mangrove di Dusun Pandansari didukung oleh hasil joint research antara Badan Perencanaan Pembangunan Daerah (BAPPEDA) Kabupaten Brebes dengan Universitas Gadjah Mada pada tahun 2016, yang menyimpulkan bahwa kawasan hutan mangrove di Dusun Pandansari paling sesuai untuk dikembangkan menjadi daya tarik wisata berbasis ekowisata. Berdasarkan hasil penelitian tersebut, menurut Mashadi, seluas 40 ha kawasan hutan mangrove telah disiapkan untuk kegiatan ekowisata. 


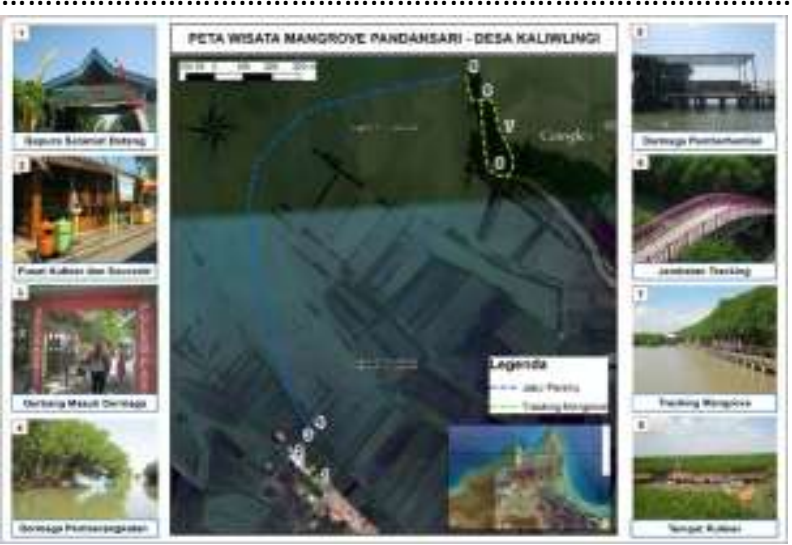

Gambar 2 Peta Wisata Desa Wisata Mangrove Sari

Sumber:

https://ppdas.geo.ugm.ac.id/2017/08/08/ekowi sata-ekosistem-mangrove-di-wilayah-pesisirkabupaten-brebes/ diakses pada tanggal 28 Februari 2021

Selain potensi hutan mangrove, Dusun Pandansari juga memiliki potensi budaya berupa atraksi seni budaya Tari Sintren, Tari Dewi Mangrove, dan Tari Ronggeng Pesisiran. Sintren merupakan seni tradisi pesisiran yang melibatkan unsur magis di dalam pertunjukan tarinya dan diperankan oleh anak gadis yang masih perawan. Tari tradisional ini berangkat dari mitos yang berkembang di daerah pesisir yang menceritakan tragedi cinta antara Dewi Selasih dan Pangeran Sulandana karena tidak direstui oleh kedua orang tua masing-masing. Sehingga mereka berdua hanya bisa bertemu di alam gaib. Sementara Tari Dewi Mangrove merupakan tarian yang digubah untuk menggambarkan sejarah perjalan Desa Wisata Mangrove Sari, dan Tari Ronggeng Pesisiran merupakan tarian yang menggambarkan suasana hati penduduk Dusun Pandansari yang penuh suka cita dalam menyambut tamu yang berkunjung ke Desa Wisata Mangrove Sari.

Potensi budaya lainnya di Dusun Pandansari adalah Rajah Bumi dan Air, Merti Bumi, dan Picunan. Ketiganya merupakan ritus budaya yang diselenggarakan oleh masyarakat pesisir Kabupaten Brebes sebagai bentuk ungkapan rasa syukur kepada Tuhan Yang Maha Esa. Selain waktu pelaksanaan yang berbeda—Rajah Bumi dilaksanakan pada bulan
Januari, Merti Bumi pada bulan Muharam/Suro, dan Sedekah Laut atau Picunan dilaksanakan pada bulan Mulud-tiga ritus budaya tersebut dilaksanakan dengan peruntukan dan tata cara yang berbeda satu dengan lainnya. Rajah Bumi dilaksanakan dengan pembacaan kidung dan doa keselamatan, serta diiringi oleh lantunan musik jawa dan pasundan, Merti Bumi atau sedekah bumi dilaksanakan oleh para petani dengan upacara ritual dan pementasan wayang. Sedangkan Picunan atau sedekah laut dilaksanakan oleh para nelayan dengan mementaskan kesenian tradisional dari berbagai daerah dalam kurun waktu 1 (satu) pekan lamanya. Potensi budaya berupa ritus kebudayaan tersebut kemudian ditetapkan menjadi event tahunan di Desa Wisata Mangrove Sari bersama dengan event lainnya yaitu Jambore Mangrove, Festival Desa Pesisir, dan Mangrove Education.

Lebih lanjut, Desa Wisata Mangrove Sari juga memiliki potensi produksi ekonomi kreatif yang merupakan warisan dari leluhur masyarakat Desa Kaliwlingi, yaitu produksi garam rebus. Proses produksi garam di Desa Kaliwlingi memiliki keunikan tersendiri, karena berbahan dasar pasir pantai, dan melalui proses perebusan selama 8 (delapan) jam. Selain itu, terdapat juga sentra kerajinan batik yang menggunakan bahan dasar pewarna alami diperoleh dari mangrove dan indigo vera tinctoria. Batik dengan pewarna alami ini kemudian menjadi batik khas pesisiran Kabupaten Brebes yang terdiri dari dua jenis, meliputi batik cap maupun tulis. Desa Wisata Mangrove Sari juga memiliki produk makanan olahan yang terbuat dari sumber daya alam yang ada di Desa Kaliwlingi, seperti krupuk rumput laut rasa udang, kepiting, dan kerang, abon ikan bandeng dan kepiting, serta aneka makanan olahan yang berbahan dasar mangrove.

Berdasarkan potensi pariwisata tersebut, Dusun Pandansari kemudian diresmikan menjadi desa wisata pada tahun 2016, dengan nama Desa Wisata Mangrove Sari. Desa wisata 
ini dikelola oleh Kelompok Sadar Wisata (Pokdarwis) Dewi Mangrove Sari. Menurut salah seorang Anggota Pokdarwis penamaan Dewi Mangrove Sari terkait erat dengan mitos yang berkembang di Dusun Pandansari bahwa daerah pesisir ini dilindungi oleh seorang Dewi. Namun nama Dewi juga merupakan kependekan dari kata Desa Wisata.

Walaupun desa wisata ini secara resmi dibentuk pada tahun 2016, kunjungan wisatawan ke Desa Wisata Mangrove Sari secara resmi dibuka pada tahun 2017. Namun demikian Pokdarwis Dewi Mangrove Sari selaku pengelola sudah memberlakukan uji coba pembukaan Desa Wisata Mangrove Sari untuk kunjungan wisatawan pada tahun 2016. Selama uji coba kunjungan wisatawan dilaksanakan di Desa Wisata Mangrove Sari, tercatat sebanyak 50.000 wisatawan nusantara dan 35 wisatawan mancanegara yang melakukan kunjungan wisata di Desa Wisata Mangrove Sari.

\section{Partisipasi Masyarakat di Desa Wisata Mangrove Sari}

Dalam pelaksanaannya, Desa Wisata Mangrove Sari dikelola secara swadaya oleh masyarakat Dusun Pandansari, Desa Kaliwlingi melalui lembaga pariwisata yaitu Kelompok Sadar Wisata (Pokdarwis) Dewi Mangrove Sari. Kepengurusan Pokdarwis Dewi Mangrove Sari memiliki periode masa bakti selama 5 (lima) tahun dan pengurus yang telah berakhir masa baktinya dapat dipilih kembali dalam Musyawarah Bersama Pokdarwis Dewi Mangrove Sari.

Pemilihan Pengurus pokdarwis dilaksanakan secara langsung, bebas dan rahasia melalui mekanisme sistem pemungutan suara (voting). Setiap anggota mengajukan minimal 1 (satu) nama Bakal Calon Ketua Pokdarwis, kemudian usulan dengan perolehan suara terbanyak ditetapkan sebagai Calon Ketua Umum. Selanjutnya Para Anggota memilih salah satu calon untuk menjadi Ketua, dan menetapkan calon dengan suara terbanyak sebagai Ketua Umum. Sedangkan calon lainnya secara otomatis ditetapkan menjadi pengurus Pokdarwis Dewi Mangrove Sari. Pemilihan pengurus ini dilakukan dalam Musyawarah Bersama Pokdarwis Dewi Mangrove Sari yang diselenggarakan setiap 5 (lima) tahun sekali. Dalam struktur kepengurusan Pokdarwis Dewi Mangrove Sari terdiri dari beberapa elemen masyarakat di Desa Kaliwlingi yang meliputi Tokoh Pegiat Lingkungan, Tokoh Masyarakat, dan Masyarakat Desa Kaliwlingi.

Pengurus Pokdarwis dalam pelaksanaannya, selain memiliki kewenangan untuk mengelola sumber daya pariwisatanya, juga dapat menjalin kerjasama dan kemitraan dengan berbagai pihak untuk kemajuan organisasi dan kesejahteraan masyarakat desa. Kewenangan Pokdarwis tersebut ditetapkan di dalam dokumen Anggaran Rumah Tangga Pokdarwis Dewi Mangrove Sari, sebagai acuan operasional organisasi.

Struktur kepengurusan Pokdarwis dapat dilihat pada Gambar 3 di bawah ini.

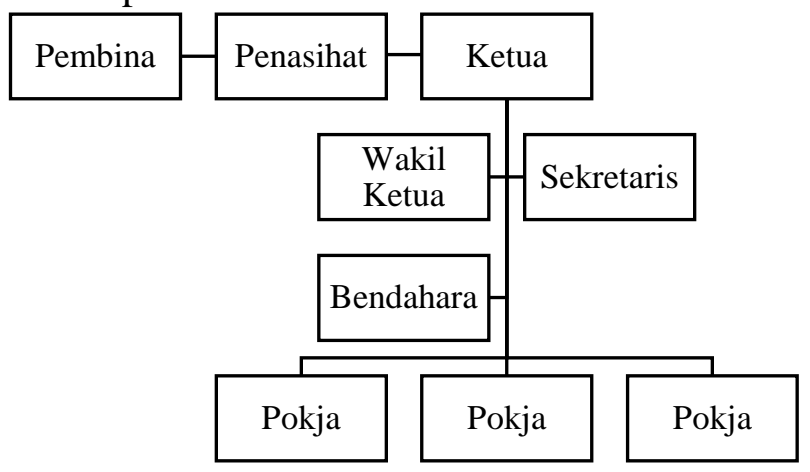

Gambar 3 Struktur Organisasi Pokdarwis Dewi Mangrove Sari

Sumber: Hasil Olah Data Penelitian, 2021

Berdasarkan Dokumen Anggaran Dasar dan Anggaran Rumah Tangga (AD/ART) Pokdarwis Mangrove Sari, terdapat 3 (tiga) jenis keanggotaan dalam Pokdarwis ini, yaitu: 1) anggota biasa, 2) anggota luar biasa, dan 3) simpatisan. Anggota Biasa merupakan anggota yang aktif dalam kegiatan kepariwisataan dan mempunyai kedudukan tercatat sebagai pengurus pokdarwis atau Perintis dan Pembina Pokdarwis Dewi Mangrove Sari. Anggota Luar Biasa adalah anggota yang terdaftar tetapi tidak aktif dan mempunyai kedudukan tercatat 
sebagai pengurus Pokdarwis atau pakar dan tenaga ahli khusus yang di butuhkan sesuai dengan kemampuan yang tidak dimiliki oleh masyarakat pandansari. Sedangkan Simpatisan adalah para sukarelawan yang memiliki simpati dan kepedulian terhadap organisasi Pokdarwis Dewi Mangrove Sari.

Anggota Biasa Pokdarwis Dewi Mangrove Sari selain wajib untuk mengikuti pertemuan tri wulanan atau pertemuan lainnya yang diselenggarakan oleh masing-masing Pokja sesuai kesepakatan para anggota pokja masing-masing, juga diwajibkan untuk mematuhi semua ketentuan yang tertuang dalam AD/ART Pokdarwis Dewi Mangrove Sari. Para Anggota juga berhak untuk mendapatkan informasi dan promosi pariwisata, serta berhak untuk mendapatkan pelatihan keterampilan dan pembinaan yang diselenggarakan baik oleh Pemerintah, maupun pihak-pihak lain melalui Pokdarwis Dewi Mangrove Sari.

Pengelola Desa Wisata Mangrove Sari membuka peluang sebesar-besarnya kepada masyarakat Desa Kaliwlingi untuk terlibat dan berpartisipasi dalam pembangunan pariwisata di desanya dengan menjadi anggota pada 12 Kelompok Kerja. Partisipasi masyarakat dalam pengelolaan Desa Wisata Mangrove Sari diwujudkan dalam pembentukan 12 kelompok kerja (Pokja) dalam struktur organisasi Pokdarwis Dewi Mangrove Sari. Kelompok kerja (Pokja) tersebut terdiri atas:

1. Pokja Manajemen Pengelolaan;

2. Pokja Ticketing;

3. Pokja Dermaga 1 \& Operator Kapal;

4. Pokja Dermaga 2 \& Pulau Pasir;

5. Pokja Tracking Mangrove;

6. Pokja Homestay;

7. Pokja Kuliner \& Pedagang;

8. Pokja Kerajinan \& Ekonomi Kreatif;

9. Pokja Daya Tarik Wisata Event \& Atraksi;

10. Pokja Bank Sampah \& Kebersihan Lingkungan;

11. Pokja Promosi \& Guide;

12. Pokja Water Sport \& Pemancingan.
Selain itu, Pokdarwis Dewi Mangrove Sari juga memberlakukan aturan yang menetapkan bahwa hanya anggota masyarakat Desa Kaliwlingi saja yang dapat membuka usaha jasa pariwisata di Desa Wisata Mangrove Sari. Hal ini pun dibenarkan oleh salah satu Pemilik Rumah Makan di Kawasan Hutan Mangrove, bahwa hanya masyarakat Desa Kaliwlingi saja yang dapat membuka usaha, dan menjadi anggota Pokdarwis Dewi Mangrove Sari. Keterlibatan masyarakat Desa Kaliwlingi sebagai anggota kelompok kerja di Pokdarwis, menunjukkan peran penting masyarakat sebagai lokomotif pariwisata berbasis masyarakat di Desa Wisata Mangrove Sari.

Implementasi Pariwisata Berbasis Masyarakat di Desa Wisata Mangrove Sari

Konsep Pariwisata berbasis masyarakat atau Community-Based Tourism (CBT) merupakan alat pembangunan kapasitas masyarakat yang bertujuan untuk memperkuat kemampuan masyarakat desa dalam mengelola sumberdaya pariwisata sambil memastikan keterlibatan masyarakat [21]-[23]. Mengacu pada batasan pengertian tersebut, konsep Pariwisata Berbasis Masyarakat di Desa Wisata Mangrove Sari diterapkan melalui Kelembagaan Pariwisata dalam bentuk Kelompok Sadar Wisata (Pokdarwis) yang melibatkan masyarakat setempat.

Kelembagaan Pariwisata ini menjadi wadah organisasi bagi masyarakat untuk menyampaikan serta memastikan aspirasinya dapat terserap dengan baik dalam pengelolaan sumber daya pariwisata dan dalam pelaksanaan pembangunan pariwisata di desanya. Selain itu, melalui lembaga pariwisata berupa Pokdarwis ini, masyarakat desa setempat kemudian secara legal dapat menjadi aktor utama dalam tahapan pembangunan pariwisata di Desa Kaliwlingi. Walaupun demikian, mengacu pada dokumen Anggaran Rumah Tangga Pokdarwis Dewi Mangrove Sari pengurus Pokdarwis juga dapat menjalin kemitraan dengan berbagai pihak untuk memajukan kelembagaan dan mensejahterakan masyarakat. Penerapan 
Pariwisata Berbasis Masyarakat di Desa Wisata Mangrove Sari dapat dilihat pada gambar 4 berikut ini.

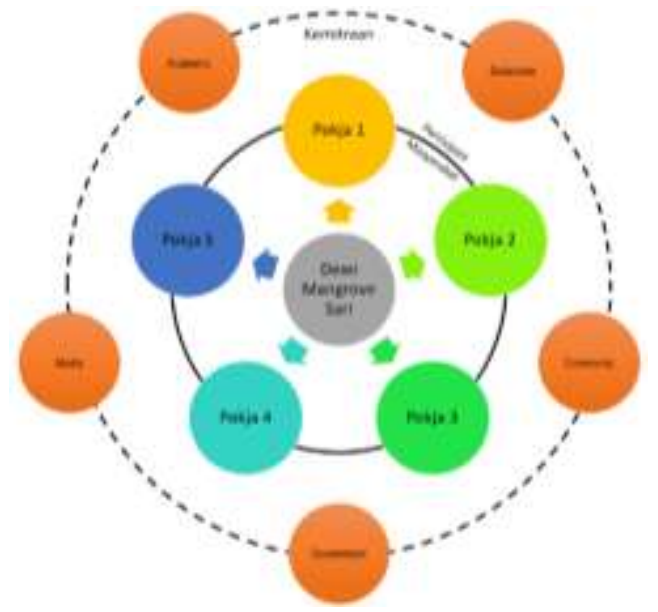

\section{Gambar 4 Model Implementasi CBT di Desa Wisata Mangrove Sari}

Sumber: Hasil Olah Data Penelitian, 2021

Berdasarkan model implementasi

Pariwisata Berbasis Masyarakat di Desa Wisata Mangrove Sari tersebut di atas, dapat dilihat dominasi keterlibatan partisipasi masyarakat dalam pengembangan pariwisata di Desa Wisata Mangrove Sari melalui beberapa Kelompok Kerja (Pokja) yang bernanung di bawah Pokdarwis Dewi Mangrove Sari. Partisipasi masyarakat dalam pengembangan pariwisata merupakan upaya distribusi ulang kekuasaan kepada masyarakat, yang sebelumnya dikucilkan dari proses politik dan ekonomi, kemudian dilibatkan dalam proses pengambilan keputusan, perencanaan, pengelolaan, dan distribusi manfaaat ekonomi [39]. Sehingga berdasarkan distribusi kekuasaan dalam pembuatan keputusan tersebut, partisipasi masyarakat di Desa Wisata Mangrove Sari dapat digolongkan kepada jenis partisipasi masyarakat "pembuatan keputusan lokal" [40]. Masyarakat Desa Kaliwlingi membuat keputusan baik secara individu maupun dalam kelompok tanpa komunikasi yang terorganisir dengan pihak luar. Hubungan dengan pihak luar bersifat konsultatif, dan opini serta saran pihak luar dapat dijadikan bahan pertimbangan tetapi tetap tidak mempengaruhi proses pengambilan keputusan.

\section{PENUTUP \\ Kesimpulan}

Seperti yang telah disampaikan dalam analisis di atas, Desa Wisata Mangrove Sari dikelola oleh masyarakat Desa Kaliwlingi melalui kelembagaan pariwisata berupa Kelompok Sadar Wisata (Pokdarwis) Dewi Mangrove Sari. Kelembagaan pariwisata yang beranggotakan masyarakat setempat merupakan salah satu indikator penting dalam tahapan pengembangan pariwisata berbasis masyarakat [21], [24]. Selain itu, keberadaan Pokdarwis yang sepenuhnya beranggotakan masyarakat desa setempat menunjukkan bahwa pengembangan pariwisata berbasis masyarakat di Desa Wisata Mangrove Sari telah sampai pada tahapan kesuksesan, karena telah mengalami proses transisi dari model kepemimpinan local champion dalam pengembangan pariwisata berbasis masyarakat menjadi manajemen organisasi berbasis masyarakat yang lebih luas [14].

Kelembagaan pariwisata yang berupa Pokdarwis juga menunjukkan bahwa partisipasi masyarakat Desa Kaliwlingi dalam pengembangan Desa Wisata Mangrove Sari berada pada tingkatan "pembuatan keputusan lokal" yang berarti bahwa masyarakat Desa Kaliwlingi mampu dan berdaulat dalam membuat keputusan pengembangan pariwisata di desanya tanpa komunikasi yang terorganisir dengan pihak-pihak luar. Walaupun demikian, masyarakat dapat melakukan konsultasi dengan pihak luar untuk memperoleh saran dan masukan sebagai bahan pertimbangan dalam proses pengambilan keputusan untuk pengembangan pariwisata berbasis masyarakat di Desa Wisata Mangrove Sari [40].

Berdasarkan hasil analisis pada artikel ini ditemukan dua faktor penting yang menentukan keberhasilan dalam pengembangan pariwisata berbasis masyarakat di Desa Wisata Mangrove Sari, yaitu organisasi masyarakat dan tingkat distribusi kekuasaan pada partisipasi masyarakat. Sehingga studi tentang faktor penentu keberhasilan penerapan pariwisata 
berbasis masyarakat di Desa Wisata Mangrove Sari perlu dilakukan lebih lanjut. Mengingat pengetahuan tentang faktor penentu keberhasilan CBT di desa pesisir seperti Desa Kaliwlingi sangat diperlukan untuk mengembangkan pariwisata di desa dengan karakteristik yang serupa.

\section{Saran}

Mengingat analisis artikel ini hanya terbatas pada bagaimana penerapan konsep pariwisata berbasis masyarakat di Desa Wisata Mangrove Sari, perlu dilakukan penelitian lebih lanjut mengenai faktor penentu keberhasilan dan aktor yang berperan dalam pengembangan CBT di Desa Wisata Mangrove Sari. Selain itu, karena obyek penelitian ini adalah desa wisata, perlu juga dilakukan analisis terhadap pengelolaan desa wisata dalam perspektif pariwisata berbasis masyarakat.

\section{DAFTAR PUSTAKA}

[1] Gubernur Jawa Tengah, Rencana Induk Pembangunan Kepariwisataan Provinsi Jawa Tengah Tahun 2012-2027. Indonesia, 2012, pp. 1-29.

[2] A. N. Andina, S. Barokah, O. A. D. Wulandari, A. A. Girsang, and R. A. N. Afifah, "Strategi Pengembangan Ekowisata Hutan Mangrove Pandansari Kabupaten Brebes untuk Mengurangi Kemiskinan," Syntax Lit. J. Ilm. Indones., vol. 5, no. 7, pp. 1-43, 2020.

[3] E. Kavita and J. Saarinen, "Tourism and rural community development in Namibia: Policy issues review," Fennia, vol. 194, no. 1, pp. 79-88, 2016.

[4] S. Koot, V. J. Ingram, and M. Bijsterbosch, "State paternalism and institutional degradation at Treesleeper Eco-camp: Community-based tourism and the loss of sovereignty among Bushmen in Namibia," Dev. South. Afr., vol. 37, no. 3, pp. 432445, 2020.

[5] F. Higgins-Desbiolles, "The "war over tourism': challenges to sustainable tourism in the tourism academy after COVID-19," J. Sustain. Tour., vol. 29, no. 4, pp. 551569, 2020.
[6] D. Dinarto, A. Wanto, and L. C. Sebastian, "COVID-19 : Impact on Bintan's Tourism Sector," Rajaratnam Sch. Int. Stud., vol. No. 033, 2020.

[7] W. Strielkowski, "COVID-19 recovery strategy for tourism industry COVID-19 recovery strategy for tourism industry," no. March, pp. 1-3, 2020.

[8] A. Ianioglo and M. Rissanen, "Global trends and tourism development in peripheral areas," Scand. J. Hosp. Tour., vol. 20, no. 5, pp. 520-539, 2020.

[9] OECD, OECD tourism trends and policies 2018, vol. 48, no. 01. 2018.

[10]E. Chiodo, H. L. Adriani, F. P. Navarro, and R. Salvatore, "Collaborative Processes and Collective Impact in Tourist Rural Villages - Insights from a Comparative Analysis between Argentinian and Italian Cases," Sustainability, vol. 11, no. 2, p. 432, 2019.

[11]J. Joo, J. J. Choi, and N. Kim, "Examining roles of tour dure producers for social capital and innovativeness in communitybased tourism," Sustain., vol. 11, no. 19, 2019.

[12] K. Pasanchay and C. Schott, "Communitybased tourism homestays' capacity to advance the Sustainable Development Goals: A holistic sustainable livelihood perspective," Tour. Manag. Perspect., vol. 37, no. December 2020, p. 100784, 2021.

[13] O. Gohori and P. van der Merwe, "Towards a tourism and community-development framework: An African perspective," Sustain., vol. 12, no. 13, 2020.

[14]K. X. H. Nagy and A. E. Segui, "Experiences of community-based tourism in Romania: chances and challenges," $J$. Tour. Anal., vol. 27, no. 2, pp. 143-163, 2020.

[15]F. Rafi and H. Herdiansyah, "The Impact of Koja Cliff Development on SocialCultural and Economic: Case of Community-Based Tourism, Banten, Indonesia," Geoj. Tour. Geosites, vol. 28, no. 1, pp. 164-174, 2020. 
[16] Suranto, B. E. Soetjipto, H. Wahyono, A. Haryono, and S. A. Rodzalan, "Community based tourism: Revitalization of villages through Bamboo plantation conservation," Humanit. Soc. Sci. Rev., vol. 7, no. 2, pp. 331-339, 2019.

[17]P. S. S. Lin and W. C. Lin, "Rebuilding relocated tribal communities better via culture: Livelihood and social resilience for disaster risk reduction," Sustain., vol. 12, no. 11, 2020.

[18]M. Polnyotee and S. Thadaniti, "Community-based tourism: A strategy for sustainable tourism development of Patong Beach, Phuket Island, Thailand," Asian Soc. Sci., vol. 11, no. 27, pp. 90-98, 2015.

[19]T. Tarnanidis and J. Papathanasiou, "Sustainable entrepreneurship : What it is ? Can we measure it?," in 4th National Symposium \& 26th National Conference on Operational Research, 2015, no. June 2015.

[20]P. Espeso-Molinero and M. J. PastorAlfonso, "Governance, community resilience, and indigenous tourism in Nahá, Mexico," Sustain., vol. 12, no. 15, 2020.

[21] A. Hamzah, Z. Khalifah, H. N. Ismail, N. H. Baharudin, L. Bhaskaran, and R. Nooruddin, Handbook on Community Based Tourism "How to Develop and Sustain CBT.” 2009.

[22]A. Hamzah, "Critical Success Factors for Creating Community-Based Tourism," in The Wiley Blackwell Companion to Tourism, First Edit., vol. 1, A. A. Lew, C. M. Hall, and A. M. Williams, Eds. John Wiley \& Sons, Ltd, 2014, pp. 499-599.

[23] V. Nair and A. Hamzah, "Successful community-based tourism approaches for rural destinations: The Asia Pacific experience," Worldw. Hosp. Tour. Themes, vol. 7, no. 5, pp. 429-439, 2015.

[24]P. Suansri, Community based tourism handbook. 2003.

[25] S. Asker, L. Boronyak, N. Carrard, and M. Paddon, Effective Community Based
Tourism, no. June. 2010.

[26] Y. Ohe, "Community-based tourism in rural Japan: The case of a network-making non-profit organization," WIT Trans. Ecol. Environ., vol. 227, pp. 11-19, 2018.

[27] A. Stoffelen, B. Adiyia, D. Vanneste, and N. Kotze, "Post-apartheid local sustainable development through tourism: an analysis of policy perceptions among 'responsible' tourism stakeholders around Pilanesberg National Park, South Africa," J. Sustain. Tour., vol. 28, no. 3, pp. 414-432, 2020.

[28] A. Yanes, S. Zielinski, M. D. Cano, and S. Il Kim, "Community-based tourism in developing countries: A framework for policy evaluation," Sustain., vol. 11, no. 9, pp. 1-23, 2019.

[29] H. Han, T. Eom, A. Al-Ansi, H. B. Ryu, and W. Kim, "Community-based tourism as a sustainable direction in destination development: An empirical examination of visitor behaviors," Sustain., vol. 11, no. 10, 2019.

[30] S. Khalid, M. S. Ahmad, T. Ramayah, J. Hwang, and I. Kim, "Community empowerment and sustainable tourism development: The mediating role of community support for tourism," Sustain., vol. 11, no. 22, 2019.

[31]L. Khartishvili, A. Muhar, T. Dax, and I. Khelashvili, "Rural tourism in Georgia in transition: Challenges for regional sustainability," Sustain., vol. 11, no. 2, pp. 1-20, 2019.

[32]B. Peredo and S. Wurzelmann, "Indigenous tourism and social entrepreneurship in the Bolivian Amazon: Lessons from San Miguel del Bala," Int. Indig. Policy J., vol. 6, no. 4, 2015.

[33]B. Sarr, M. M. González-Hernández, J. Boza-Chirino, and J. de León, 'Understanding communities' disaffection to participate in tourism in protected areas: A social representational approach," Sustain., vol. 12, no. 9, 2020.

[34]T. J. SETOKOE, "Community-based 
tourism: A panacea for community development in nqileni village, eastern cape, south africa," Geoj. Tour. Geosites, vol. 34, no. 1, pp. 28-32, 2021.

[35]A. Amin and Y. Ibrahim, "Model of Sustainable Community Participation in Homestay Program," Mediterr. J. Soc. Sci., vol. 6, no. 3, pp. 539-545, 2015.

[36]A. Arintoko, A. A. Ahmad, D. S. Gunawan, and S. Supadi, "Communitybased tourism village development strategies: A case of Borobudur tourism village area, Indonesia," Geoj. Tour. Geosites, vol. 29, no. 2, pp. 398-413, 2020.

[37]K. N. Lindström and M. Larson, "Community-based tourism in practice: evidence from three coastal communities in Bohuslän , Sweden," Bull. Geogr. Socio-economic Ser., vol. 33, no. 33, pp. 71-78, 2016.

[38]R. Siri and O. S. Chantraprayoon, "Local community participatory learning with a nature interpretation system: A case study in Ban Pong, Sansai district, Chiang Mai, Thailand," Kasetsart J. Soc. Sci., vol. 38, no. 2, pp. 181-185, 2017.

[39]S. R. Arnstein, "A Ladder Of Citizen Participation. Journal of the American Institute of Planners," J. Am. Inst. Plann., vol. 35, no. November 2012, pp. 37-41, 1969.

[40]P. N. Thomas and E. van de Fliert, Interrogating the Theory and Practice of Communication for Social Change: The Basis for a Renewal, First Edit. London: Palgrave Macmillan, 2014.

[41]J. W. Creswell, Research Design: Qualitative, Quantitative, and Mixed Methods Approaches, Fourth Edi. California: SAGE Publications Ltd, 2014.

[42]R. K. Yin, Case Study Research and Applications: Design and Methods Sixth, Sixth Edit. Los Angeles: SAGE Publications Ltd, 2018.

[43] Sudaryono, Metodologi Penelitian: Kuantitatif, Kualitatif dan Mix Method, Edisi Kedu., vol. 2, no. 1. Jakarta: PT.
Rajagrafindo Persada, 2018.

[44]M. B. Miles, A. M. Huberman, and J. Saldana, Qualitative Data Analysis: a Methods Sourcebook, Third Edit. Arizona: SAGE Publications Ltd, 2014.

[45] T. Puspitarini and A. K. Laturiuw, "Dewi Mangrove Sari, Gadis Cantik Yang Lahir di Tengah Bencana," Sabdamas, pp. 173181, 2019. 


\section{HALAMAN INI SENGAJA DIKOSONGKAN}

